\title{
CORRELATION OF PELVIC ORGAN PROLAPSE QUANTIFICATION TECHNIQUE WITH PELVIC FLOOR DYSFUNCTION SYMPTOMS
}

\author{
Pradhan $T^{1^{*}}$, Hakkim $M^{2}$, Thapa $B D^{3}$, Bhatta $R D^{1}$, Rai $R^{1}$, Rijal $P^{4}$
}

\section{Affiliation}

1 Associate Professor, Department of Obstetrics and Gynaecology, BPKIHS.

2 Junior Resident, Department of Obstetrics and Gynaecology, BPKIHS.

3 Assistant Professor, Department of Obstetrics and Gynaecology, BPKIHS.

4. Additional Professor, Department of Obstetrics and Gynaecology, BPKIHS.

\section{ARTICLE INFO}

\section{Article History}

Received : 16 July, 2018

Accepted : 18 November, 2018

Published : 31 December, 2018

(C) Authors retain copyright and grant the journal right of first publication with the work simultaneously licensed under Creative Commons Attribution License CC - BY 4.0 that allows others to share the work with an acknowledgment of the work's authorship and initial publication in this journal.

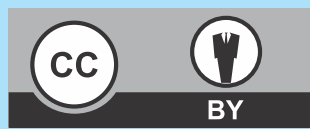

\section{ORA 84}

DOI: $\underline{10.3126 / \text { bjhs.v3i3.22169 }}$

\author{
* Corresponding Author \\ Dr. Tarun Pradhan \\ Associate professor \\ Department of Obstetrics and Gynaecology \\ B. P. Koirala Institute of Health Sciences \\ E-mail: tarunsriti@gmail.com \\ ORCID: https://orcid.org/0000-0001-6446-7986
}

\section{Citation}

Pradhan T, Hakim M, Thapa BD, Bhatta R, Rai R, Rijal P.Correlation of Pelvic Organ Prolapse Quantification Technique with Pelvic Floor Dysfunction Symptoms. BJHS 2018;3(3)7: 528-531.

\section{ABSTRACT}

\section{Introduction}

Assessment of POP by POP-Q gives anatomical site-specific measurement, which helps in surgery, follow-up and reduces inter-observer variation. The Pelvic Floor Distress Inventory (PFDI) is condition-specific health-related quality of life questionnaires for women with pelvic floor disorders.

\section{Objective}

To assess pelvic organ prolapse by POP-Q technique and to correlate pelvic floor distress inventory questionnaire with POP-Q segments.

\section{Methodology}

A prospective study was done from March 2014 to February 2015 after ethical approval from IRC, B.P. Koirala Institute of Health Sciences. All patients with pelvic organ prolapse were included after informed verbal consent. The patients were then asked questions as in pelvic floor distress inventory questionnaire (PFDI) and noted in performa. The patients were then examined by POP-Q technique and noted. The informations were entered in the MS excel chart and statistical analysis done using SPSS 11.5.

\section{Results}

There were 72 patients enrolled. The mean age of patients was 53.65 years. Majority of patients were found to have stage 4 prolapse (43.1\%).

POP-Q examination showed majority of patients had anterior and apical compartment defect. Correlation between POP-Q points and urinary symptoms showed significant relation with points in anterior compartment, genital hiatus and perineal bodies. Correlation with POP-Q points with colorectal symptoms showed involvement of genital hiatus significantly with strain stool and incomplete bowel movement. Correlation with pelvic distress symptoms with POP-Q sites showed significant relation with bulging, push up vagina for urination and defecation.

\section{Conclusion}

POP-Q site specific points showed significant correlation with symptoms from Pelvic Floor Distress Inventry (PFDI) questionnaires.

\section{KEYWORDS}

Pelvic Organ Prolapse, POP-Q, PFDI 


\section{INTRODUCTION}

Pelvic organ prolapse (POP) is a common, benign condition in women. For many women it can cause vaginal bulge and pressure, voiding dysfunction, defecatory dysfunction, and sexual dysfunction, which may adversely affect quality of life. ${ }^{1}$ Pelvic organ prolapse is the health concern affecting millions of women worldwide. The global burden of disease 2010 reported recently the estimated prevalence of POP to be around $9 \%$ world wide. ${ }^{2}$ Worldwide, POP risk factors include early marriage, high parity, squatting during delivery, prolonged labour, increasing age, menopause, hysterectomy, smoking, obesity, heavy lifting, and early return to work after parturition.

Pelvic organ prolapse is considered a major cause of maternal morbidity in low income country, the estimated figure was considered to be closer to $20 \%$ with wide variations among different populations. ${ }^{4}$ In Nepal, pelvic organ prolapse prevalence is estimated at $10 \%$ among women of reproductive age (between 15 and 49 years) and $24 \%$ among post menopausal women between 45 to 49 years. ${ }^{5,6}$ The occurrence of POP shows significant difference among ethnicity, level of education and occupation of respondents. The risk factors are mainly related with parity, gravida, age of last child birth and work after delivery.

The Pelvic Floor Distress Inventory (PFDI) is conditionspecific health-related quality of life questionnaires for women with pelvic floor disorders. ${ }^{8}$ PFDI and Pelvic floor impact questionnaire are validated questionnaires to assess effect on health related quality of life due to prolapse, focusing on urinary symptoms, colo-rectal symptoms, pelvic floor distress symptoms. ${ }^{9,10}$

Pelvic Organ prolapse quantification (POP-Q) technique is a validated tool to measure pelvic organ prolapse. ${ }^{11}$

It helps in site-specific measurement of different compartment of prolapsed segment as anterior compartment, apical and posterior compartment ${ }^{11}$ plotted in three by three grids, which helps in correlating with pelvic floor dysfunction symptom and further helps in pre-operative planning for site specific pelvic floor reconstruction. It can also be used for post-operative assessment by comparing with preoperative site-specific measurements of pelvic organ prolapse.

The objective of the study was to assess pelvic organ prolapse by POP-Q technique and to correlate pelvic floor distress inventory questionnaire with POP-Q measurements.

\section{METHODOLOGY}

This is a prospective study done from March 2014 to February 2015 after ethical approval from Institutional Review Committee (IRC), B.P.Koirala Institutes of Health Sciences (BPKIHS). All patients with pelvic organ prolapse were included after informed verbal consent. The patients were explained regarding the study and briefed about questionnaires in native language. The patients were then asked quality of life questionnaires regarding urinary symptoms, colo-rectal symptoms and pelvic distress symptoms due to pelvic organ prolapse as in pelvic floor distress inventory questionnaire (PFDI) and noted in performa. The patients were then examined for pelvic organ prolapse by POP-Q technique by trained gynaecologist and noted.
The information was entered in the MS excel chart and statistical analyses were done using SPSS 11.5. Frequency and means were calculated for demographic variables. Chi-square test and pearsons' correlation test was applied for assessing relations between POP and patients symptoms from PFDI. Level of significance was considered to be $p<0.05$.

\section{RESULTS}

There were 72 patients enrolled during study duration. The age of patient ranged from $26-75$ years. The mean age of patients was 53.65 years. Among 72 patients 57 (79.2\%) were post menopausal. Fifty-three $(73.6 \%)$ had more than two children and majority patients were found to have stage 4 pelvic organ prolapse $(43.1 \%)$.

POP-Q examination showed majority of patients had anterior and apical compartment defect involving points $\mathrm{Aa}$, $\mathrm{Ba}, \mathrm{C}$ (Table.1). Correlation between POP-Q points and urinary symptoms like urge incontinence, dribbling, difficulty in evacuating bladder and pain lower abdomen showed significant relation with defect in anterior compartment, genital hiatus and perineal bodies in POP-Q. Increased frequency and dribbling also showed significant relation with point $D$ (Table. 2). Colorectal-Anal symptoms didn't show significant relation with most POP-Q sites except genital hiatus measurement was significantly related with straining for stool and incomplete bowel movement (Table.3). Correlation with pelvic distress symptoms with POP-Q points showed significant relation with bulging symptoms with involvement of anterior, apical aswell as posterior vaginal segments. Requiring pushing up vagina for defecation showed involving $\mathrm{Ba}, \mathrm{C}$ and $\mathrm{Bp}$. Defect in perineal body in POP-Q showed patients to have symptoms of incomplete voiding sensation and requiring pushing up vagina during urination (Table.4).

$\begin{array}{cc}\begin{array}{c}\text { Table 1: Distribution of POP-Q outside hymen } \\ \text { POP- Q points }\end{array} & \text { Outside hymen (\%) } \\ \text { Aa } & 47(65 \%) \\ \text { Ba } & 58(80 \%) \\ \text { C } & 45(62 \%) \\ \text { Ap } & 28(39 \%) \\ \text { Bp } & 37(47 \%) \\ \text { D } & 15(21 \%)\end{array}$

Table. 2 Correlation between urinary symptoms and POP-Q measurement

PQOL symptom
domain

\section{domain}

Frequency

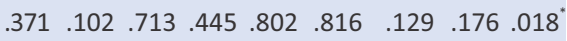

Urge

\begin{tabular}{lllllllll} 
Incontinence & $.047^{*} .021^{*} .198$ & .365 & $.015^{\circ}$ & .817 & .900 & .368 & .605 \\
\hline $\begin{array}{l}\text { Stress } \\
\text { Incontinence }\end{array}$ & .060 & $.013^{*} .435$ & .691 & .430 & .414 & .910 & .323 & .622
\end{tabular}

Incontinence

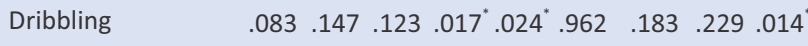

Difficulty in evacuating bladder

$.041^{*} .063 .004^{*} .133 \quad 979.743 .629 .309$

Pain in lower

abdomen 


\begin{tabular}{|c|c|c|c|c|c|c|c|c|c|}
\hline P-QOL symptom domain & $\mathrm{Aa}$ & $\mathrm{Ba}$ & C & Gh & $\mathrm{Pb}$ & Tvl & Ap & Bp & D \\
\hline Strain Stool & .127 & .398 & .164 & $.006^{*}$ & .280 & .949 & .078 & .198 & .199 \\
\hline Incomplete bowel movement & .558 & .535 & .748 & $.007^{*}$ & .695 & .285 & .905 & .806 & .827 \\
\hline Formed stool incontinence & .387 & .105 & .130 & .771 & .422 & .414 & .079 & .051 & .202 \\
\hline Loose stool incontinence & .387 & .105 & .130 & .771 & .422 & .414 & .079 & .051 & .202 \\
\hline Air incontinence & .389 & .106 & .129 & .760 & .413 & .442 & .071 & .051 & .200 \\
\hline Pain during defecation & .872 & .519 & .654 & .707 & .063 & .439 & .310 & .888 & .091 \\
\hline Rectal prolapse & .075 & .061 & .091 & .875 & .283 & .537 & $.004^{*}$ & .036 & $.003^{*}$ \\
\hline Bowel urgency & .285 & .425 & .266 & .084 & .065 & .066 & .078 & .086 & .075 \\
\hline
\end{tabular}

*: Level of Significance, $p<0.05$

Table.4: Correlation between Pelvic Distress Inventory 6(POPDI- 6) and POP-Q points.

\begin{tabular}{lccccccccc} 
P-QOL symptom domain & $\mathrm{Aa}$ & $\mathrm{Ba}$ & $\mathrm{C}$ & $\mathrm{Gh}$ & $\mathrm{Pb}$ & $\mathrm{Tvl}$ & $\mathrm{Ap}$ & $\mathrm{Bp}$ & $\mathrm{D}$ \\
Pressure Abdomen & 652 & .792 & .887 & .843 & .454 & .368 & .427 & .624 & .241 \\
\hline Heaviness & .057 & .109 & .104 & .225 & .569 & .492 & .063 & .075 & $.034^{*}$ \\
\hline Bulging & $014^{*}$ & .016 & .001 & .050 & .644 & .745 & .068 & $.036^{*}$ & $.022^{*}$ \\
\hline $\begin{array}{l}\text { Push up vagina to initiate } \\
\text { defecation }\end{array}$ & .051 & $.030^{*}$ & $.042^{*}$ & .055 & .183 & .128 & .386 & $.041^{*}$ & .088 \\
\hline $\begin{array}{l}\text { Incomplete Bladder voiding } \\
.503\end{array}$ & .548 & .348 & .136 & $.045^{*}$ & .055 & .929 & .458 & .675 \\
\hline $\begin{array}{l}\text { Push up vagina } \\
\text { to initiate voiding }\end{array}$ & .167 & .095 & .069 & $.019^{*}$ & $.009^{*}$ & .141 & .737 & .119 & .079 \\
\hline
\end{tabular}

\section{DISCUSSION}

Out of 72 patients enrolled, POP-Q examination showed majority of patients to have grade 4 pelvic organ prolapse mostly involving anterior and apical compartment.

Pelvic Organ Support Study (POSST) described the distribution of pelvic organ support in a gynecologic clinic population to define the clinical disease state of pelvic organ prolapse and to analyze its epidemiologic condition. The population consisted of 1004 women who were aged 18 to 83 years. The prevalence of pelvic organ prolapse quantification stages was $24 \%$ (stage 0 ), $38 \%$ (stage 1 ), $35 \%$ (stage 2 ), and $2 \%$ (stage 3 ). In contrast, our study showed majority of patients with stage 4 pelvic organ prolapse. ${ }^{12}$

Study done on functional symptoms and associations of women with genital prolapse showed SUI, urgency, and voiding difficulties as common urinary symptoms and defecatory dysfunction, anal incontinence as colo-rectal symptom and anterior vaginal wall prolapse were found the most common. Similar to our study, anterior segment prolapse was found to be common and significant correlation was found between push up on the bulge to initiate or complete urination and point $\mathrm{Gh}$ and $\mathrm{Pb} .^{13}$

The relationship of vaginal prolapse severity to symptoms and quality of life showed the stage of prolapse was significantly higher in those symptomatic of prolapse. There was no correlation between urinary symptoms and uterovaginal prolapse severity whereas bowel symptoms were strongly associated with posterior vaginal wall prolapse. This result is contrary to our result where we found the relationship between bladder symptoms and POP-Q points. ${ }^{14}$

Extent of uterovaginal prolapse when compared with bowel dysfunction symptoms with questionnaires showed no relation with the severity of posterior vaginal prolapse. ${ }^{15}$

Study done on functional bowel and anorectal disorders in patients with pelvic organ prolapse and incontinence showed, there was a high prevalence of constipation and anorectal pain disorders in women with urinary incontinence and pelvic organ prolapse. However, patients with stage 3 or 4 pelvic organ prolapse had similar rates of constipation compared with those with urinary incontinence. Constipation and its subtypes were not related to the stage of pelvic organ prolapse. It appeared that either constipation was not a significant contributor to prolapse, or constipation contributes equally to the development of both urinary incontinence and pelvic organ prolapse. $^{16}$

Vaginal descent and pelvic floor symptoms in postmenopausal 
women were studied to determine whether vaginal descent changes were associated with pelvic floor symptoms in postmenopausal women. Increasing apical descent (point C) was associated with "see/feel a bulge", increasing anterior descent (point $\mathrm{Ba}$ ) with bladder pain and obstructive bladder scores, and increasing posterior descent (point $\mathrm{Bp}$ ) with the bowel incontinence score. ${ }^{17}$ Most of the result were similar to our result except posterior descent and bowel incontinence.

\section{CONCLUSION}

Pelvic Floor Distress Inventory (PFDI) questionnaire and POP-Q points showed significant relation with various pelvic organ prolapse symptoms. However, since anterior and apical segments with were predominantly involved in POP-Q eamination, urinary and pelvic distress symptoms showed more significant relation than bowel dysfunctions.

\section{RECOMMENDATION}

Though, PFDI and POP-Q measurements shows significant correlation in different aspects of questionaires. Large population studies is requird to help in formulating recommendations regarding its use in clinical practice.

\section{LIMITATION OF THE STUDY}

Study would have been more strong with large population and also if we could have followed up the patients postoperative for re-questionnaire and POP-Q examination to evaluate the improvements in site-specific defects and in symptoms due to pelvic floor dysfunctions.

\section{ACKNOWLEDGEMENT}

My sincere thanks to our team of co-authors for there effort in data collection and entry. My regards to Dr. Surya Niraula for helping us with the statistics.

\section{CONFLICT OF INTEREST}

None declared

\section{FUNDING}

None

10. Utomo E, Blok BF, Steensma AB, Korfage. Validation of the Pelvic Floor Distress Inventory (PFDI-20) and Pelvic Floor Impact Questionnaire (PFIQ-7) in a Dutch population. Int Urogynecol J 2014; 25 : 531-44. PMID:24445668 DOI:10.1007/s00192-013-2263-z

11. Bump RC, Mattiasson A, B $\varnothing$ K, Brubaker LP, DeLancey JO, Klarskov P et al. The standardization of terminology of female pelvic organ prolapse and pelvic floor dysfunction. Am J Obstetrics and Gynecology 1996; 175:10. PMID: 8694033.

12. Swift S, Woodman P, O'Boyle A, Kahn M, Valley M, Bland D, Wang W, Schaffer J. Pelvic Organ Support Study the distribution, clinical definition, and epidemiologic condition of pelvic organ support defect. Am J Obstet Gynecol 2005; 192 (3): 795-806. PMID: 15746674. DOI: 10.1016/j.ajog.2004.10.602

13. Adjoussou SA, Bohoussou E, Bastide S, Letouzey V, Fatton B, de Tayrac R. Functional symptoms and associations of women with genital prolapse. Prog Urol2014;24 (8):511-7. PMID: 24875570. DOI: 10.1016/j.purol.2013.11.015

14. Digesu G.A, Chaliha C, Salvatore S, Hutchings A, Khullar V. The relationship of vaginal prolapse severity to symptoms and quality of life. Bjog 2005; 112 (7): 971-6. https://doi.org/10.1111/j.14710528.2005.00568.x

15. Weber AM, Walters MD, Ballard LA, Booher DL, Piedmonte MR. Posterior vaginal prolapse and bowel function. Am J Obstet Gynecol 1998;179(6):1446-9. PMID: 9855579

16. Jelovsek JE, Barber MD, Paraiso MF, Walters MD. Functional bowel and anorectal disorders in patients with pelvic organ prolapse and incontinence. Am J Obstet Gynecol 2005;193 (6): 2105-11. PMID: 16325624. DOI: 10.1016/j.ajog.2005.07.016

17. Bradley CS, Zimmerman MB, Wang Q, Nygaard IE. Vaginal descent and pelvic floor symptoms in postmenopausal women: a longitudinal study. Obstet Gynecol 2008; 111 (5): 1148-53. PMID: 18448748. DOI: 10.1097/AOG.0b013e31816a3b96 